\title{
Câncer de mama: da descoberta à recorrência da doença
}

\section{Breast cancer: of the discovery to the recurrence of the illness}

\author{
Cáncer de mama: de la descubierta a la recurrencia de la enfermedad
}

\author{
Luana de Sousa Pinho', Antonia do Carmo Soares Campos", Ana Fátima Carvalho Fernandes "', \\ Sâmya Aguiar Lobo ${ }^{\mathrm{V}}$
}

\section{RESUMO}

Estudo exploratório e descritivo que objetivou compreender 0 sentimento da mulher mastectomizada desde o diagnóstico até a possibilidade da recorrência do câncer de mama, desenvolvido com 15 mulheres com as idades compreendidas entre 30 a 75 anos, participantes do Grupo de Auto-ajuda, Ensino, Pesquisa e Assistência à Mulher Mastectomizada da Universidade Federal do Ceará. Os dados foram coletados entre os meses de agosto e setembro/2004, mediante entrevista semi-estruturada. Dos dados analisados identificamos as seguintes categorias: a descoberta do câncer e a realização da mastectomia, a expectativa de cura diante do câncer, convivendo com o temor da recorrência e a significação do grupo de auto-ajuda em suas vidas. Constatamos que o diagnóstico do câncer de mama se apresenta como algo irreal em suas vidas, se constituindo em doença letal e assustadora, trazendo surpresa, medo e desespero. O grupo de autoajuda surge como apoio, onde essas mulheres interagem, trocam e compartilham experiências, tornando-se mais conscientes, superando juntas o temor da recorrência do câncer de mama.

Palavras chave: Câncer de mama; Mastectomia; Recorrência; Saúde da mulher; Cuidados de enfermagem.

\section{ABSTRACT}

This in an exploratory and descriptive study, which aimed to understand the feelings of the mastectomized woman due to the possibility of breast cancer recurrence since the diagnosis, it was developed with 15 mastectomized women with the average of age between 30 and 75 years, participants of GEPAM (Self-Help, Teaching, Research and Attendance to the mastectomized woman Group) from the Department of Nursing of UFC. The data were collected in 2004, between August and September, with a semi-structured interview.
We identified the following categories: the discovery of cancer and the accomplishment of the mastectomy; the cure expectation before the cancer; living with the fear of the recurrence and the significance of the group of self-help in their lives. We verified that the breast cancer diagnosis presents itself as something unreal in their lives, consisting of a lethal and frightening disease, bringing surprise, fear and despair. The self-help group appears as support, where those women interact, change and share experiences, becoming more conscious, overcoming together the fear of the recurrence of breast cancer.

Key words: Breast neoplasms; Mastectomy; Recurrence; Women's health ; Nursing care.

\section{RESUMEN}

Estudio exploratorio y descriptivo, objetivo comprehender el sentimiento de la mujer mastectomizada desde el diagnóstico hasta la posibilidad de la recurrencia del cáncer de mama, desarrollado con 15 mujeres mastectomizadas con edades comprehendidas entre 30 a 75 años, participantes del Grupo de Auto ayuda, Enseñanza, Investigación y Asistencia a la Mujer Mastectmomizada, del Departamiento de Enfermería de la Universidad Federal de Ceará. Los datos fueron colectados en agosto y septiembre/ 2004, através de

\footnotetext{
Enfermeira Especialista em Neonatologia pela Universidade Federal do Ceará. Fortaleza-CE. E-mail: luaninhadesousa@bol.com.br

Enfermeira.Doutora em Enfermagem.Docente da Universidade de Fortaleza-UNIFOR. Fortaleza-CE. E-mail: toniacampos@unifor.br

III Enfermeira.Doutora em Enfermagem. Docente da Universidade Federal do Ceará. Fortaleza-CE

E-mail: afcsaraiva@yahoo.com.br

Iv Acadêmica de Enfermagem da Universidade Estadual do Ceará. Bolsista FUNCAP, Membro do Projeto Saúde da Mulher da Universidade Federal do Ceará (UFC). E-mail: samya_lobo@hotmail.com
} 
Pinho LS, Campos ACS, Fernandes AFC, Lobo SA. Câncer de mama: da descoberta à recorrência da doença. Revista Eletrônica de Enfermagem [serial on line] 2007 Jan-Abr; 9(1): 154-165. Available from: URL: http://www.fen.ufg. br/revista/v9/n1/v9n1a12.htm

entrevista estructura en parte. De los datos analizados, identificamos las seguientes categorías: la descubierta del cáncer y la realización de la mastectomía; la expectativa de cura delante del cáncer, viviendo junto al miedo de la recurrencia y a la significación del grupo de auto ayuda en sus vidas. Constatamos que el diagnóstico del cáncer de mama se presenta como algo que no es real en sus vidas, constuyéndose en una enfermedad asustadora, lo que trae surpresa, miedo y

\section{NTRODUÇÃO}

O câncer de mama é uma doença heterogênea e complexa, que se apresenta de múltiplas formas clínicas e morfológicas, com diferenças na pré e pós-menopausa, com diferentes graus de agressividade tumoral e potencial metastástico, atingindo frequentemente mulheres após os quarenta anos de idade, embora se tenha observado um fenômeno em nível mundial, do aumento de sua incidência em faixas etárias mais jovens. (1)

Segundo a Organização Mundial da Saúde estima-se que, por ano, ocorram mais de 1.050.000 novos casos de câncer de mama em todo o mundo tornando-o ainda mais comum entre as mulheres. Estima-se que 48.930 casos de câncer de mama serão registrados no Brasil. (2)

Embora o Ministério da Saúde tenha se esforçado em campanhas educativas na detecção precoce, através de campanhas preventivas, como o incentivo à realização do auto-exame das mamas pelas mulheres, o uso de uma terapêutica adequada e de um tratamento multidisciplinar, definindo assim estratégias a serem priorizadas para seu controle, o câncer de mama ainda constitui-se na primeira causa de morte por câncer, entre además desespero. El grupo de auto ayuda surge como apoyo, en que esas mujeres interagen, cambian experiencias, lo que resultan en mujeres más conscientes, superando todavia juntas el miedo de la recurrencia del cáncer de mama.

Palabras clave: Neoplasias de la mama; Mastectomía; Recurrencia; Salud de la Mujer; Atención de enfermería.

as mulheres, registrando de duas décadas: a taxa de mortalidade padronizada por idade, por 100.000 mulheres, aumentou de 5,77\% em 1979, para $9,74 \%$ em $2000^{(2)}$.

O câncer de mama é uma doença que apresenta diferentes situações de ameaça aos seus portadores, trazendo desconforto psicológico, o que gera ansiedade e um estado depressivo na mulher; mudanças no seu estilo de vida causado por desconforto físico e pelo conceito de sua auto-imagem, gerando baixaestima e libido sexual diminuído, o medo quanto ao sucesso do tratamento, assim como a possibilidade de sua recorrência e o temor da morte ${ }^{(3)}$.

O tratamento do câncer de mama deve ser abordado por uma equipe multidisciplinar, sendo realizado de forma integral e em conjunto para fornecer melhores subsídios de recuperação ao paciente. As modalidades terapêuticas disponíveis atualmente são a cirúrgica (mastectomia) e a radioterápica para o tratamento loco-regional, e ainda a hormonioterapia e quimioterapia para o tratamento sistêmico ${ }^{(4)}$.

Apesar do diagnóstico tardio e de, muitas vezes, casos da ineficácia de seu tratamento, a maioria das mulheres acometidas por essa doença ainda viverá por muitos anos. Diante 
Pinho LS, Campos ACS, Fernandes AFC, Lobo SA. Câncer de mama: da descoberta à recorrência da doença. Revista Eletrônica de Enfermagem [serial on line] 2007 Jan-Abr; 9(1): 154-165. Available from: URL: http://www.fen.ufg. br/revista/v9/n1/v9n1a12.htm

desse aumento de sobrevida é importante a compreensão de como conviver com essa doença, na presença constante da incerteza da falência de seu tratamento e o medo da sua recorrência.

A tentativa de compreender o processo que envolve desde o diagnóstico da patologia até o período operatório com o cotidiano norteado de dúvidas e incertezas, o medo da operação, a incerteza do tratamento e até mesmo o medo da recorrência da doença, nos despertou a curiosidade acerca do tema e nos levou a realizar uma visita a um grupo de autoajuda, de mulheres mastectomizadas que se encontram contando, umas às outras, suas experiências, dificuldades, barreiras, assim como suas vitórias e suas conquistas diante da doença.

A mastectomia ainda é um dos tratamentos a que a maioria das mulheres com câncer é submetida. É uma intervenção temida e que por fazer parte do tratamento, interfere no estado físico, emocional e social, resultando na mutilação de uma região do corpo que desperta libido e desejo sexual. Esse processo interfere na sexualidade, na auto-imagem e na estética feminina, hoje em dia muito valorizada e ressaltada. Além dessa dimensão que simboliza a sexualidade, as mamas ainda são relacionadas a importante função da maternidade, pois essas ao produzirem leite representam o sustento dos primeiros meses de vida de qualquer ser humano ${ }^{(5)}$.

Observamos da convivência com as mulheres nessa situação que a mastectomia é um trauma nas suas vidas, cuja cirurgia provoca sentimentos de perda, mutilação e incerteza do tratamento. Porém a troca de energia, solidariedade e a esperança da cura total que uma transmite a outra no contexto do grupo de ajuda é algo surpreendente, pela força que um momento tão frágil de suas vidas suscita para dar apoio umas às outras que se encontram na mesma situação, não desistindo e lutando pela vida ${ }^{(6)}$.

O viver com uma doença estigmatizante, como o câncer de mama, conviver com sentimentos negativos e enfrentar preconceitos dá margem a um processo de significação, gerado pela percepção que as mulheres têm sobre a doença, possibilitando-Ihes elaborar novos conceitos sobre ter uma doença incurável. Esse processo é resultado ainda da interpretação da experiência de viver com a doença e seu tratamento, o que gera sentimentos e atitudes que refletem um grau de incerteza a partir da revelação do diagnóstico e das suas concepções a respeito da doença e possibilidades da recorrência da doença ${ }^{(7)}$

Esse sentimento de incerteza deve ser compreendido e analisado de forma que possibilite a apreensão da complexidade que envolve o contexto da doença, tendo em vista as dificuldades no diagnóstico, na realização do tratamento e no enfrentamento dos sentimentos de impotência diante do sofrimento e da insegurança de cura que a própria doença transmite. Esse processo traz ainda o medo constante de sua recorrência, o que é elemento importante na vida dessas mulheres, que influencia sua auto-organização e reformulação de sua visão de vida, assim como a expectativa de vivenciar um novo mundo ${ }^{(7)}$.

Tendo em vista os aspectos até aqui relacionados, estudar estes aspectos é relevante para a enfermagem, visto que a 
Pinho LS, Campos ACS, Fernandes AFC, Lobo SA. Câncer de mama: da descoberta à recorrência da doença. Revista Eletrônica de Enfermagem [serial on line] 2007 Jan-Abr; 9(1): 154-165. Available from: URL: http://www.fen.ufg. br/revista/v9/n1/v9n1a12.htm

doença e seu tratamento trazem mudanças no estado psicológico das mulheres, que vivem em constante ameaça e dúvida acerca da sua cura diante do câncer de mama. Nesse sentido é importante avaliar, conhecer esse mundo norteado de dúvidas e de sentimentos a que essa mulher é submetida para melhor compreender novas expectativas de sua cura e de vida, bem como pensar estratégias de cuidados de enfermagem mais assertivos para esse grupo.

Diante do exposto, este estudo objetiva compreender o sentimento da mulher mastectomizada no diagnóstico e na possibilidade da recorrência do câncer de mama.

\section{METODOLOGI A}

Estudo do tipo descritivo e exploratório, que tem como objetivo primordial a descrição das características de determinada população ou fenômeno ou, então, o estabelecimento de relações entre variáveis, e são inúmeros os estudos que podem ser classificados sob este título ${ }^{(8)}$. Foi desenvolvido no grupo de autoajuda, de uma Universidade Pública do Ceará. Esse grupo foi criado em 1998, e se constitui num grupo aberto, onde participam efetivamente cerca de 20 mulheres e tem como intuito oferecer atenção e apoio à mulher mastectomizada.

Os sujeitos da pesquisa foram 15 mulheres que realizaram a cirurgia de mastectomia e que atualmente encontram-se em fase de controle e recuperação, das quais duas sofreram com a recorrência do câncer de mama. A faixa etária variou de 30 a 75 anos. Quanto ao estado civil, seis são casadas, três solteiras, duas viúvas e quatro desquitadas.
Em relação ao grau de instrução, três possuem o ensino médio, uma está cursando supletivo do ensino médio, cinco possuem o ensino fundamental completo e seis, o ensino fundamental incompleto. Suas ocupações variam entre dedicação ao lar, venda de artesanatos e confecção de sutiãs com prótese mamária, costura realização de feiras e brechós, e outras são aposentadas.

Os critérios para inclusão dessas mulheres na pesquisa foram: aceitar participar da pesquisa de forma espontânea mediante convite e esclarecimento; ter realizado a cirurgia de mastectomia; participar efetivamente do grupo de auto-ajuda, participar das atividades propostas pela pesquisadora, debates e dinâmicas, regularmente.

Os dados foram coletados no período de agosto a setembro de 2004, no dia das reuniões semanais, que acontecem às sextasfeiras, no turno da manhã, e duraram cerca de duas horas.

Inicialmente, foram realizadas dinâmicas de reconhecimento do grupo e debates sobre câncer de mama e o impacto na vida social, para que, assim, houvesse maior entrosamento entre a pesquisadora e os sujeitos da pesquisa aumentando os laços de confiança, cumplicidade e descontração. Em seguida, foi realizada uma entrevista semi-estruturada, abordando dados de identificação das participantes e questionamentos pertinentes à pesquisa. Esta entrevista foi realizada individualmente com cada mulher pesquisada. $\mathrm{Na}$ medida em que as participantes respondiam aos questionamentos novas interrogativas iam surgindo contribuindo para o enriquecimento do conteúdo da pesquisa. 
Pinho LS, Campos ACS, Fernandes AFC, Lobo SA. Câncer de mama: da descoberta à recorrência da doença. Revista Eletrônica de Enfermagem [serial on line] 2007 Jan-Abr; 9(1): 154-165. Available from: URL: http://www.fen.ufg. br/revista/v9/n1/v9n1a12.htm

O presente trabalho foi aprovado pelo Comitê de Ética em Pesquisa da Universidade Federal do Ceará - UFC, conforme é exigido pela Resolução 196/96 sobre pesquisa em seres humanos, respeitando a liberdade de sua participação e conservando o anonimato dos mesmos $^{(9)}$.

$\mathrm{Na}$ aproximação com as prováveis participantes do estudo foi formulado o convite para participarem, e, na ocasião, foi esclarecido quanto aos objetivos da pesquisa, da adesão espontânea, sendo apresentado o termo de consentimento esclarecido, assinado por estas e pela pesquisadora. Sendo-Ihes garantido o direito ao anonimato, sigilo, acesso aos dados e a liberdade de se retirarem do estudo a qualquer momento, sem que esse fato representasse qualquer tipo de prejuízo para si, bem como que os dados somente seriam utilizados na presente pesquisa.

Após o término da coleta dos dados foi realizada a transcrição, na íntegra, da fala das participantes, pelas próprias pesquisadoras. A seguir, a partir das leituras do formulário preenchido e releitura das falas nas entrevistas realizadas, esses dados foram analisados e categorizados ${ }^{(8)}$ de acordo com as unidades de significação contidas nas falas e nas entrevistas, sendo identificadas as seguintes categorias: a descoberta do câncer e a realização da mastectomia; a expectativa diante da cura; convivendo com o temor da recorrência.

Para garantir 0 anonimato às participantes deste estudo, as mulheres foram identificadas por codinomes de flores, a nossa opção deveu-se ao fato das flores estarem presentes em todos os momentos da vida do ser humano, sejam eles alegres, festivos ou tristes.

\section{ANÁLI SE E DESCRI ÇÃO DOS DI SCURSOS}

Concluída a etapa de coleta de dados, afastamo-nos do nosso objeto de investigação, para avaliarmos o conteúdo das entrevistas. Nesta etapa, apresentamos as categorias, ilustrando com a fala das mulheres os aspectos que serão analisados a seguir:

\section{A descoberta do câncer e a realização da mastectomia}

As mulheres, em seu processo de socialização, muitas vezes são obrigadas a suportar sofrimentos de várias ordens, mas diante do diagnóstico do câncer de mama, essas mulheres se deparam com sentimentos diversos, como: angústia, dor, sofrimento, culpa. Esses sentimentos são constantes na mulher desde o diagnóstico da doença até o seu processo de cura ${ }^{(3)}$.

As preocupações sobre a ameaça à vida e à saúde, bem como o medo do desfiguramento, invalidez e angústia associados ao tratamento são comuns para todas as mulheres que enfrentam um diagnóstico de câncer de mama ${ }^{(10)}$.

Diante da descoberta do câncer, o desespero foi o sentimento mais relatado entre as mulheres estudadas, muitas vezes deixando-se extravasar através do choro. O câncer de mama em suas vidas se constituía como um mito, sem possibilidades de acometêlas e diante do diagnóstico inesperado, o desespero foi um modo encontrado para o extravasamento de suas emoções e decepções diante do diagnóstico: 
Pinho LS, Campos ACS, Fernandes AFC, Lobo SA. Câncer de mama: da descoberta à recorrência da doença. Revista Eletrônica de Enfermagem [serial on line] 2007 Jan-Abr; 9(1): 154-165. Available from: URL: http://www.fen.ufg. br/revista/v9/n1/v9n1a12.htm

Nunca achei que poderia ficar com essa doença, nunca tive problemas de saúde, quando soube que estava com ela me desesperei (Tulipa).

Fiquei desesperada, chorei muito, lembrei dos meus filhos, do meu marido (Girassol).

Meu pensamento ficou vago, não conseguia mais pensar em nada, sofri muito (Gardênia).

Ter recebido o diagnóstico do câncer de mama e ter convivido com ele foi um momento carregado de medo e incertezas. A sensação de estar com o câncer era sinônimo de morte, que geralmente está associado a um estigma ao diagnóstico da doença que amedronta e abala psicologicamente e socialmente a vida dessas mulheres.

O sentimento de medo é freqüentemente associado à palavra câncer, pois algumas mulheres carregam o estigma de uma doença letal e assustadora, transmitindo toda a vivência de uma cultura na qual ter câncer é sinônimo de morte ${ }^{(11)}$.

Esse sentimento pode ser observado em vários depoimentos quando indagadas sobre a reação diante do diagnóstico da doença:

Senti medo, chorei muito, fiquei pensando porque aquilo estava acontecendo comigo (Tulipa)

Tive medo de morrer, deixar meus filhos, quem ia cuidar deles pra mim? (Bugari).

Além do impacto de uma doença imprevisível, com ameaça de perda da vida, o câncer de mama tem ainda um fator agravante, pois as mamas simbolizam sua feminilidade e acumulam funções estéticas, eróticas e de troca de afetividade e de alimento, através da amamentação. A mastectomia, como tratamento, altera essa feminilidade se constituindo na mutilação de um órgão que para as mulheres tem uma função tão importante; além de distanciá-las dos padrões estéticos tão valorizados na sociedade atual.

Saí do consultório, fui pra casa de minha filha, abracei bastante meu neto, minha família, pensei que teria pouco tempo com eles (Rosamélia).

Os problemas no contexto familiar parecem ter surgido ou se intensificado a partir do aparecimento do câncer em um membro da família. As formas de reagir a esses problemas se manifestaram de acordo com os recursos disponíveis e com o modo de ser de cada mãe. O modo de ser adotado por cada indivíduo em seu mundo depende de seu grau de liberdade, da forma que sua família lhe faz perceber o mundo, como esse aspecto lhe é mostrado e de como é percebido por ele ${ }^{(12)}$.

No contexto social, embora o processo de adoecimento e sofrimento trate de experiências individuais e singulares é por meio do relacionamento com os outros que os sujeitos mobilizam o seu interior e conseguem expressar suas emoções e sentimentos, pois a privação das relações sociais leva as pessoas a perderem a referência, a sua identidade ${ }^{(13)}$.

$\mathrm{Em}$ relação à mastectomia como tratamento, observamos sentimentos de tristeza, depressão e aceitação. A tristeza pela perda da mama foi um relato freqüente entre as pesquisadas, e essa tristeza foi relacionada à mutilação de uma parte do corpo, alterando sua auto-imagem corporal, fugindo dos padrões de beleza definidos atualmente:

Não queria nem ver o local, fiquei muito triste (Cravo). 
Pinho LS, Campos ACS, Fernandes AFC, Lobo SA. Câncer de mama: da descoberta à recorrência da doença. Revista Eletrônica de Enfermagem [serial on line] 2007 Jan-Abr; 9(1): 154-165. Available from: URL: http://www.fen.ufg. br/revista/v9/n1/v9n1a12.htm

Achei feio, chorava muito, faltava parte de mim (Rosa).

Algumas mulheres revelaram que se sentiram depressivas. A depressão é uma das características psicológicas das mulheres com câncer de mama, podendo estar presente em dois ou mais anos após o diagnóstico, manifestando-se através de angústias, sentimentos de culpa e insegurança ${ }^{(13)}$.

A depressão, muitas vezes, estava associada à sua própria imagem construída em pensamentos, após a realização da mastectomia e a preocupação com a opinião dos filhos, marido e familiares sobre a sua nova imagem:

Não gostava de me olhar, fiquei pensando se eu não gosto imagina meu marido (Cravo).

Não deixo ninguém ver até hoje, no início me senti muito feia, chorava todos os dias (Rosa).

Fiquei deprimida, triste tinha um seio e o outro não, é meio estranho (Cecília).

A aceitação diante da mastectomia surge como uma chance de cura diante da doença e uma necessidade para se evitar a morte. Essa mulher, então, passa a aceitar sua nova forma física adquirindo ter uma nova concepção da realidade. $\mathrm{O}$ apoio familiar diante do tratamento é algo que também contribui para essa aceitação, traz apoio, força e desperta coragem diante da cura.

Sei que iam tirar uma coisa que estava podre dentro de mim (Rosamélia).

Só pensava em ficar curada, se para isso era preciso tirar o seio, não me importei (Girassol).

Meu marido conversou bastante comigo, disse que o importante era minha vida (Margarida).
Minha mãe me deu muita força (...), no dia da cirurgia ficou comigo até o fim esperando, aceitei a mastectomia, tinha certeza que ia me curar (Verbena).

A mulher quando recebe o diagnóstico de câncer de mama passa a ter muitas dúvidas, questionamentos, devido à doença trazer muito sofrimento, uma vez que a terapia agressiva provoca angústia, dor da mutilação de um órgão que representa a maternidade, a estética e a sexualidade feminina. Ela se preocupa em dar continuidade ao tratamento, em se reabilitar, vendo a necessidade de recuperar sua auto-estima e sua imagem corporal. Para isso, é de fundamental importância o suporte social e da família e de auto- cuidado(14).

\section{A expectativa da cura diante do câncer}

A maioria das mulheres que participaram da pesquisa tinha pensamento positivo diante da doença e eram confiantes na cura e na luta pela vida. Era freqüente a referência na crença em Deus para buscar equilíbrio emocional. Essa crença divina Ihes dá esperança e certeza diante da cura, como se Deus fosse uma força curativa, um ser supremo capaz de conceber a cura através da fé.

Tenho fé em Deus que estou curada, estou curada ( Rosa).

Já to boa, em nome de Jesus (Adália).

Deus sabe o que passei, o quanto já sofri, ele não quer ver as pessoas doentes não(...) (Gardênia).

Culturalmente, a religião tem várias funções: possibilita a criação de uma identidade de coesão entre as pessoas, ajuda no enfrentamento das ameaças e possibilita ganhar novas energias para lutar pela 
Pinho LS, Campos ACS, Fernandes AFC, Lobo SA. Câncer de mama: da descoberta à recorrência da doença. Revista Eletrônica de Enfermagem [serial on line] 2007 Jan-Abr; 9(1): 154-165. Available from: URL: http://www.fen.ufg. br/revista/v9/n1/v9n1a12.htm

sobrevivência, na situação da doença fatal. Com fé religiosa, os pacientes, em geral, passam a fazer um discurso de uma pessoa melhor, mais forte, que prega a solidariedade, com a participação ativa do grupo social. Ao afirmarem que a religião ajuda a vencer o medo da morte, das perdas, do sofrimento e na afirmação da expectativa da cura das doenças, as pessoas afirmaram a restituição do significado da vida ${ }^{(15)}$.

Mesmo aquelas que passavam pela recorrência do câncer de mama, a fé em Deus e a crença num milagre como fenômeno para a cura estava presente, sendo relatada da seguinte forma:

O câncer está em mim de novo, mas Deus é capaz de todas coisa, rezo para que me dê a cura (Rosamélia).

O meu braço inchou todo, ele curou, agora rezo para que nada mais grave me aconteça, vai me dá a cura, tenho fé (J asmim).

A crença religiosa possibilita as mulheres com câncer de mama se sentirem em paz na sua condição, para, assim, viver com maior otimismo. A experiência do câncer é um processo que desafia a pessoa e, para tanto, ela busca algo com o qual possa enfrentar esses desafios. Por isso, a religião é descrita como estratégia valorizada na cultura ocidental para lidar com a doença e suas terapêuticas ${ }^{(16)}$.

Um estudo revela que para pessoas acometidas por problemas oncológicos, a prática religiosa era uma estratégia de recuperação das forças perdidas com a doença e os tratamentos realizados, a religião influencia a sobrevivência delas ${ }^{(17)}$.
Realizar corretamente o tratamento, cuidar do corpo, da mente e fazer a prevenção também são citadas como formas para a cura. Muitas delas relatam que antes este cuidado era subsidiado por outros afazeres, como cuidar dos filhos, do marido, da casa, mas que hoje em dia, cuidar de seu bem estar é algo fundamental para seu processo de saúde:

Eu não me tratava bem. Agora depois da doença faço todos os meus exames, vou sempre no médico e assim acredito na cura (violeta).

Se não me tratar posso até ficar com a doença, mas me trato, então não vem (Rosa).

Hoje em dia, minha filha, me cuido (Violeta).

As mulheres estudadas retomaram a sua vida procurando adotar hábitos saudáveis, revelando um aumento no cuidado com sua saúde depois do diagnóstico do câncer de mama e terem se tornando pessoas mais amáveis, menos rancorosas, buscando a prática de sentimentos bons, procurando abster-se dos sentimentos ruins, elegendo essas práticas para o aumento da auto-estima, acreditando, assim, que isso colabora para a recuperação da sua saúde e adequação ao seu novo estilo de vida.

Depois dessa doença passei a me ver com outros olhos, aprendi a cuidar de mim (Bugari).

Eu caminho, brinco com todo mundo, sou mais feliz hoje, venho pro grupo(...), antes só ficava em casa (Girassol).

Conheço mais gente, me cuido mais, é tudo altoastral aqui(Tulipa).

Muitas sobreviventes do câncer de mama relatam tomar maior cuidado consigo mesmo na descoberta da doença e procuram adotar 
Pinho LS, Campos ACS, Fernandes AFC, Lobo SA. Câncer de mama: da descoberta à recorrência da doença. Revista Eletrônica de Enfermagem [serial on line] 2007 Jan-Abr; 9(1): 154-165. Available from: URL: http://www.fen.ufg. br/revista/v9/n1/v9n1a12.htm

estilo de vida mais saudável. Estes fatos colaboram no processo de reabilitação, pois parece renovar os valores, crenças e atitudes da mulher no sentido de buscar novas maneiras para viver satisfatoriamente. Essas ações construtivas contribuem para elevação da auto-estima dando maior expectativa diante da cura ${ }^{(18)}$.

\section{Convivendo com o temor da recorrência}

O temor da recorrência do câncer foi uma experiência compartilhada por todas as mulheres estudadas, se mostrando como uma constante em suas vidas visto por elas como capaz de acometer qualquer uma, a qualquer instante.

Em algumas mulheres, esse temor era mais freqüente diante da proximidade das consultas médicas de revisão, ao fazer os exames de rastreamento, como o auto-exame das mamas, mamografias, durante as sessões de fisioterapia reabilitadora, enfim quando surge a lembrança do diagnóstico inicial, gerando a expectativa de um provável novo diagnóstico de recidiva, trazendo sentimentos de angústia a essa mulher ${ }^{(19)}$.

Quando vou ao médico, fico preocupada com o resultado dos meus exames (Cecília).

Não deixo de fazer meus exames nunca mais, mas tenho medo de fazer e dá de novo a doença (Adália).

Nas mulheres em que o processo de recuperação estava ocorrendo sem intercorrências, esse temor foi demonstrado como medo diante da recidiva do nome e do significado da doença, lembrado por todas pelos momentos ruins desde o descobrimento da patologia até a realização da mastectomia, e a recorrência representava à tona todos esses sentimentos já vivenciados, que muitas delas tentam esquecer.

Tenho medo de acontecer tudo novamente, não quero aquilo de novo pra mim não (Violeta).

O câncer pode voltar a qualquer hora, às vezes penso que estou curada, mas não estou (Crisantina).

Deus me livre tudo novamente, mas pode acontecer com qualquer uma de nós (Verbena).

Quando perguntadas sobre o porquê desse temor, as mulheres apoiaram-se em experiências vivenciadas por outras mulheres dizendo o que ocorreu com muitas conhecidas. O câncer é visto como uma doença imprevisível, que traz incertezas diante da cura total e esse sentimento é compartilhado com outras mulheres em consultas médicas de revisão, entre o grupo de auto-ajuda e nos encontros de mulheres mastectomizadas. Os seguintes depoimentos retratam essas declarações:

Vejo muitos casos de recorrência do câncer, mesmo a pessoa fazendo o tratamento correto, canso de ver mulheres nas consultas, a gente fala muito sobre isso aqui, aqui mesmo no grupo tem dois casos, a Rosa mesmo estava boazinha, de repente o braço dela começou a inchar e quando foi ver lá estava o câncer (Rosa).

A gente sempre ver casos da doença acontecendo isso aí, por isso não pode confiar na cura total, sempre tem dúvida (Margarida).

Nas mulheres que estavam sendo acometidas pela recorrência do câncer de mama, o temor sempre esteve presente e com 
Pinho LS, Campos ACS, Fernandes AFC, Lobo SA. Câncer de mama: da descoberta à recorrência da doença. Revista Eletrônica de Enfermagem [serial on line] 2007 Jan-Abr; 9(1): 154-165. Available from: URL: http://www.fen.ufg. br/revista/v9/n1/v9n1a12.htm

o impacto do novo diagnóstico da recidiva da doença, o pavor e o medo diante do câncer traz a desesperança da cura. Essas mulheres relacionam seus casos como uma doença incurável, sem bom prognóstico, relacionandoo ao fato de seu diagnóstico ter sido tardio e pela demora na busca do tratamento.

Tenho metástases, sempre oro a Deus que me cure, mas não acredito, o meu caso é grave, então peço que me dê mais alguns anos de vida pra ver meu netinho crescer (Rosamélia).

Vi que estava com nódulo em casa, e demorei a procurar o médico, quando fui já era tarde, fiz o tratamento, mas não adiantou (Jasmim).

Vivenciar conscientemente essa situação leva a mulher com câncer a se distanciar do seu projeto existencial, que inclui a busca do cuidado e da cura, o que faz com que ela experiencie a angústia que também é uma possibilidade de poder tornar-se mais autêntica.

As mulheres apontam esse temor como forma alternativa para a correta prática do tratamento e do auto-cuidado. A busca pela não reincidência da doença trouxe a elas consciência da necessidade de mudar os hábitos de vida, implicando na valorização da vida e no cuidado com sua saúde.

A gente nunca pode ter certeza da cura, porque senão deixa de se tratar (J asmim).

Se a gente ficar pensando que pode voltar, se cuida melhor, porque ninguém gosta de ficar doente, ainda mais com câncer (Margarida).

Diante das novas práticas e da mudança dos hábitos de vida, a doença muda seu estilo de viver e passam a ter uma nova perspectiva em relação aos seus problemas, onde o temor da recorrência se transforma em aspecto positivo na busca pela cura, trazendo sentimentos de esperança e auto-estima diante do novo cuidado recebido por si e pelo serviço de saúde ${ }^{(20)}$.

Sei que a minha chance de ter novamente o câncer é muito pouca, antes era enorme, agora vejo, mas me cuido bem melhor que antes (Cecília)

Não corria atrás dos meus exames, era relaxada, agora faço todos, o câncer pode vir a qualquer momento, mas não vai me pegar de novo (Girassol) o hospital, cuida muito bem da gente, a gente recebe tudo que precisa, é cercado de profissionais bons (Rosamélia)

Essa preocupação constante com a cura ou com a reincidência da doença faz com que essas mulheres procurem mudanças no seu hábito de vida, além de atender com rigor às solicitações dos exames periódicos ${ }^{(5)}$.

As mulheres por precisarem conviver com as possibilidades de recidivas, exacerbações dos sintomas e pela possibilidade de ocasionar a morte, utilizam a adaptação da teoria da incerteza à doença crônica, a qual podemos afirmar que a incerteza é usada pelos indivíduos como base para sua autoorganização e reformulação da sua visão de vida ${ }^{(7)}$.

A análise dos dados nos mostra toda uma problemática vivenciada por mulheres mastectomizadas desde o diagnóstico a possível recorrência da doença. O estudo nos remeterá a um melhor planejamento da assistência de enfermagem, a fim de ajudar as mulheres a explorar sentimentos, expectativas e estratégias de ajustamento em suas vidas. 
Pinho LS, Campos ACS, Fernandes AFC, Lobo SA. Câncer de mama: da descoberta à recorrência da doença. Revista Eletrônica de Enfermagem [serial on line] 2007 Jan-Abr; 9(1): 154-165. Available from: URL: http://www.fen.ufg. br/revista/v9/n1/v9n1a12.htm

\section{CONSI DERAÇÕES FI NAIS}

O diagnóstico do câncer de mama traz diversos sentimentos e diferentes reações na vida das mulheres. Como pôde ser constado, prevalecem os sentimentos de medo e desespero, estando isso relacionado ainda ao tabu do câncer ser considerado como uma doença letal e assustadora e à improbabilidade vista por essas mulheres de serem acometidas pela doença, trazendo surpresa diante do diagnóstico do câncer.

A realização da mastectomia como tratamento surge como uma esperança diante da vida e como forma para a cura, levando, assim, à aceitação da realização desta como saída da morte. Ao longo do diagnóstico da doença até a realização da mastectomia podemos verificar sentimentos de tristeza e depressão, pela realização não somente de uma cirurgia para a cura de um mal, mas de uma mutilação de uma região do corpo relacionado com sua feminilidade que altera seus padrões estéticos e sua auto-imagem tão cultivada ao longo dos anos.

A atitude positiva diante da doença e da situação vivida foi observada na fala de todas as participantes, sendo que observamos um aumento na crença divina de Deus, como forma de cura, e mesmo naquelas que estavam sendo acometidas pela recorrência, verificamos a crença da cura esperada em forma de um milagre.

O temor da recorrência foi constante em todas as participantes, e esse temor associado à expectativa da cura faz com que as mulheres mastectomizadas realizem corretamente o tratamento, criem hábitos de vida saudáveis, aumentem o auto-cuidado e o amor a si próprias, antes Ihes negado.
Nas mulheres que estavam vivenciando a recorrência do câncer, a falta de cuidado com a saúde, o diagnóstico tardio da patologia e a demora pela procura do serviço médico especializado foram apontados como fatores desencadeadores do seu quadro atual, e mesmo com a desesperança diante da cura da doença dada através da intervenção humana, essas crêem na cura divina, sendo revogada por Deus como um milagre mostrando a sua luta e força diante da doença.

Através desse estudo percebemos a importância da enfermagem em diagnosticar as necessidades das mulheres mastectomizadas, compreendendo o significado do câncer em suas vidas e o convívio constante com o temor da recorrência, conscientizando e proporcionando meios de interação com estas pacientes, para que aumentem, assim, as suas perspectivas diante da cura, aumentando o auto-cuidado e, através da confiança na realização correta do tratamento, diminuir o temor da recorrência do mal.

\section{REFERÊNCI AS}

1. Freitas $\mathrm{F}$, Menke $\mathrm{CH}$, Passos EP, Rivoire WA. Rotinas em Ginecologia. $4^{\circ}$ ed., SP: Artmed; 2001: 340-356.

2. Brasil, Ministério da Saúde. Secretaria Nacional de Assistência à saúde. Instituto Nacional do Câncer. Estimativa da incidência por câncer no Brasil. Pro-Onco/INCA, 2006.

3. Deitos TFH, Gaspary JFP. Efeitos biopsicossociais e psiconeurológicos do câncer sobre os pacientes e familiares. Revista Brasileira de Cancerologia. Rio de Janeiro, 1997; 43(2): 117-26.

4. Veronesi U. Mastologia Oncológica. Copyright, MEDSI Editora Médica e Cientifica Itda. 2002: 319-63.

5. Halbe, MW. Tratado de Ginecologia. $2^{\circ}$ ed., SP: Roca; 1993: 54-75.

6. Ferreira MLSM, Mamede MV. Representação do corpo na relação consigo mesma após 
Pinho LS, Campos ACS, Fernandes AFC, Lobo SA. Câncer de mama: da descoberta à recorrência da doença. Revista Eletrônica de Enfermagem [serial on line] 2007 Jan-Abr; 9(1): 154-165. Available from: URL: http://www.fen.ufg. br/revista/v9/n1/v9n1a12.htm

mastectomia. Rev Latino-am Enfermagem 2003 mai-jun; 11(3): 299-304.

7. Almeida AM, Mamede MV, Panobianco MS, Prado MAS, Clapis MJ. Construindo o significado da recorrência da doença: a experiência de mulheres com câncer de mama. Rev Latino-am Enfermagem 2001 set-out; 9(5): 63-9.

8. Bardin L. Análise de conteúdo. 3o ed., Lisboa: Edições 70; 2004: 223.

9. Fortes PAC. Ética e saúde: questões éticas, deontológicas e legais, tomada ou decisões, autonomia e direitos do paciente. Estudo de casos. E. P. U., São Paulo. 1998: 119.

10. Harris JR, Lippman ME, Morrow CK. Doenças da mama. 2a ed., São Paulo: Medsi; 2002.

11. Fernandes AFC, Mamede MV. Câncer de mama: mulheres que sobreviveram. Fortaleza: UFC; 2003: 13-93.

12. Oliveira NFS, Costa SFG, Nóbrega M ML. Diálogo vivido entre enfermeira e mães de criança com câncer. Revista Eletrônica de Enfermagem. 2006; 8(1): 99-107.

13. Fernandes AFC. O cotidiano da mulher com câncer de mama. Fortaleza: Fundação Cearense de pesquisa e cultura; 1997: 13-94.

14. Ferreira MLSM, Mamede MV. Representação do corpo na relação consigo mesma após mastectomia. Rev Latino-am Enfermagem; 2003 mai-jun; 11(3):299-304.
15. Rabello MCM, Cunha LA, Schaeppi PB. Religião, imagens e experiências da aflição: alguns elementos para reflexão: in: Rabelo MCM, Alves, PC, Souza IMA, organizadoras: Experiência de doença e narrativa. Rio de Janeiro (RJ): FIOCRUZ; 1999.

16. Aquino VV, Zago MMF. O significado das crenças religiosas para um grupo de pacientes oncológicos em reabilitação. Rev Latino-am Enfermagem; 2007 jan-fev; 15(1)

17. Zago MMF, Sawada NO, Stopa MJR, Martinez EL. O significado cultural de ser laringectomizado. Rev Bras Cancerol 1998 abrjun; 44(2): 139-45.

18. Silva RM, Mamede MV. Conviver com mastectomia. Fortaleza: UFC, Departamento de Enfermagem, 1998: 139-45

19. Carvalho MVB, Merighi MAA B. O cuidar no processo de morrer na percepção de mulheres com câncer: uma atitude fenomenológica. Rev. Latino-am Enfermagem. 2005, nov-dez; 13(16): 951-9.

20. Regis MF, Simões MF. Diagnóstico de câncer de mama: sentimentos, comportamentos e expectativas de mulheres. Revista Eletrônica de Enfermagem. 2005; 07(01): 81-6.

Artigo recebido em 25.10.06

Aprovado para publicação em 30.04.07 